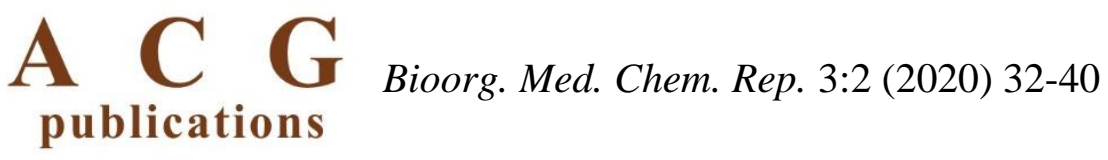

Bioorganic \&

Medicinal

Chemistry

Reports

\title{
New molecule design with in-silico methods for Covid-19 treatment
} Mehmet Abdullah Alagöz ${ }^{*}$

\author{
Department of Pharmaceutical Chemistry, Faculty of Pharmacy, Inonü University, 44280, Malatya, \\ Türkiye
}

(Received August 14, 2020; Revised September 18, 2020; Accepted September 21, 2020)

\begin{abstract}
Intensive studies are being conducted to develop effective prevention and treatment strategies for the Covid19 pandemic. During a pandemic, it is vital to act quickly to develop a defense strategy. It usually takes a long time to develop a preventive vaccine, and immediate drug development is needed to reduce the impact of the rapidly increasing Covid-19 pandemic. This study aimed to design an effective and potent drug by selecting remdesivir, a nucleotide analog prodrug that inhibits viral RNA polymerases and is known to be active against Covid-19. Remdesivir is metabolized into active nucleoside triphosphate (NTP) by the host; this metabolite competes with adenosine triphosphate (ATP) for incorporation into the nascent RNA strand. Therefore, molecular docking studies have been conducted based on NTP (the active form of remdesivir), and a target molecule that could be effective against Covid-19 has been designed.
\end{abstract}

Keywords: SARS-CoV-2; Covid-19; remdesivir; molecular docking. (O2020 ACG Publication. All rights reserved.

\section{Introduction}

Coronaviruses (CoVs) are some of the major pathogens for humans. ${ }^{1}$ It is known that coronaviruses December 2019 as a respiratory infection identified in Wuhan, China. The World Health Organization (WHO) declared the new coronavirus outbreak an international public health emergency in January 2020 and declared it a pandemic in March 2020.,3

CoVs cause a range of problems, from simple upper respiratory tract infections to serious lung diseases such as severe acute respiratory syndrome, which can be fatal. According to data reported by the WHO, Covid-19 spread to 216 countries in August 2020, causing approximately 19 million people to become ill and approximately 720 thousand to die. ${ }^{3,4}$ Covid-19 progresses with serious morbidity and mortality, and the virus spread globally in a very short time. There is no effective medicine or preventive vaccine against SARS-CoV-2. Therefore, developing an effective drug has become a necessity.

Among the basic mechanisms to prevent replication of SARS-CoV-2, one of the most effective methods is the inhibition of RNA-dependent RNA polymerase enzymes involved in viral replication. The development of inhibitory drugs against these enzymes is an extremely important focus of research. The effect of many RNA polymerase inhibitors against Covid-19 is still under investigation. ${ }^{5,6}$ Remdesivir, a nucleotide analog prodrug that inhibits viral RNA polymerases, has been reported to show in vitro activity against SARS-CoV-2. In addition, the European Union (EU) Commission approves the use of remdesivir in the treatment of Covid-19 patients., 7

Currently, there is no vaccine or a specific, effective antiviral treatment option for Covid-19. Therefore, global surveillance of Covid-19 patients is urgently needed. Although studies on the use of existing antivirals and their combined use in the treatment of Covid-19 continue, new therapeutic drug research is also ongoing, and studies are needed to develop and determine the effectiveness of these new drugs. ${ }^{9-11}$

\footnotetext{
* Corresponding author: E-Mail: mehmet.alagoz@inonu.edu.tr Phone: +90 5303285697; Fax: + 904223411217
} 
Screening and redesigning molecules with specific activity as drug candidates for certain diseases or pathogens is a reliable, time-saving, and cost-saving method. Designing molecules with, which have a very large host network, cause respiratory tract infections in humans. CoVs, which are enveloped, positivepolarity, and single-stranded RNA viruses, have a non-segmented RNA genome. The virion has four main structural proteins: Nucleocapsid $(\mathrm{N})$ protein, transmembrane $(\mathrm{M})$ protein, envelope (E) protein, and Spike (S) protein (Figure 1). ${ }^{12}$ Until 2019, there were four CoVs (HCoV-229E, HCoV-OC43, HCoV-NL63, and HCoV-HKU1) that could be transmitted to humans and cause respiratory diseases. These viruses generally cause only mild upper respiratory tract diseases but, in rare cases, can cause serious infections in infants, young children, and the elderly. However, the SARS-CoV and MERS-CoV viruses in the CoV family can infect the lower respiratory tract and cause severe respiratory syndrome in humans. ${ }^{13}$

The new type of coronavirus (SARS-CoV-2), which is the cause of Covid-19 disease, has become a significant, global problem in a very short time. Covid-19 first appeared in the world.

Computer programs is one of the most important methods in developing new drug candidates. Today, the virtual molecule scanning method is frequently used in drug development. ${ }^{14}$ This method can also be used in redesigning molecules for the treatment of Covid-19. Methods like computer-aided drug design (CADD) are of great importance in drug development for emergency situations such as Covid-19, where there the urgency of the situation is underscored by a rapid increase in deaths. CADD methodologies play an important role in the discovery of promising drug candidates. This method limits the use of animal models in pharmacological research, reduces the cost of drug discovery, and aids the rational design of new, targeted, and safe drug candidates. It also provides information about absorption, distribution, metabolism, excretion, and toxicity (ADMET) values which are important for drug molecules in terms of drug likeness. ${ }^{15-17}$ In the study it has aimed to design potential drug candidates against SARS-CoV-2 as insilico, based on the determination of pharmacophore groups of remdesivir.

This new, targeted drug design study, which, based on the activity of remdseivir, could be effective to treat Covid-19, was carried out using CADD.

\section{Experimental}

\subsection{Creating Virtual Library}

In order to develop new, effective compounds against Covid-19, the effectiveness of RNAdependent RNA polymerase inhibitors (Ribavirin, Sofosbuvir, Galidesivir, Tenofovir, Remdesivir, Telaprevir, Boceprevir, Simeprevir, and Vaniprevir) and RNA protease inhibitors (Amprenavir, Atazanavir, and Darunavir), which have different structures, have been investigated. ${ }^{18,19}$ Various common features of these RNA protease and polymerase inhibitors were determined and filtered to reduce the number of compounds in the literature and to create a virtual library. RNA polymerase and RNA protease inhibitors used in treatment had their molecular weight (MW), log P, polar surface area (PSA) values, hydrogen bond acceptor (HBA), and heteroatom numbers calculated.

The lowest and highest values of these calculated parameters were determined, and a scale was created for each parameter. For RNA polymerase inhibitors, the scales were MW: 100-800, $\log$ P: 2-6, PSA: 40-336, HBA: 9-17, and heteroatom number: 35-55. For proteases, they were MW: 500-800, $\log$ P: 2-6, PSA: 110-180, HBA: 9-15, and heteroatom number: 35-55. Approximately 2,000,000 molecules in the ChEMBL database were filtered according to the parameter scales, and approximately 100,000 molecules were determined. These molecules were downloaded in structure data file (SDF) format and prepared in the LigPrep module of Maestro program to create a virtual library.

\subsection{Molecular Docking Studies}

The 100,000 identified compounds were prepared using Maestro and the LigPrep module, and possible conformers were created. An OPLS 2005 force field was used for minimization. Epik option was used to keep the ligand in the correct protonation states in biological conditions. The 7BV2 Protein-DataBank- (PDB) coded protein was downloaded from www.rscb.org for docking studies. ${ }^{20,21}$ Using Prime (Schrödinger, LLC, NY), Impact (Schrödinger, LLC, NY), Epik (Schrödinger, LLC, NY), and Propka software, unwanted solvent molecules were cleaned; any missing amino acids, atoms, and hydrogens were added; charges were assigned; and orientations of polar hydrogen and water were adjusted in crystal 
structure. Grid maps were created using the receptor grid generation (Schrödinger, LLC, NY). Each molecule docked 100 times in extra precision mode of Glide (Schrödinger, LLC, NY). The five compounds with the highest docking score were determined. ${ }^{22-24}$

\subsection{In Silico ADMET Prediction}

Various physicochemical parameters estimated the toxicities and drug possibilities of the five target molecules using PreADMET, SwissADME web server, and Datawarrior software v4.07.02. The studies resulted in defining the some important parameters of the molecules in drug availability like rotatable bonds (RB), hydrogen bond acceptor and donor counts (HA and HD), octanol/water partition coefficient (LogP), polar surface area (PSA), Lipinski's rule of five, drug likeness score, and mutagenic and carcinogenic properties. ${ }^{25-27}$

\section{Results and Discussion}

Remdesivir has a broad spectrum of antivirals, including filoviruses, paramyxoviruses, pneumoviruses, and coronaviruses. ${ }^{28,29}$ Literature reports that remdesivir inhibits all animal and human coronaviruses tested, including SARS-CoV-2, and also shows antiviral and clinical effects against Middle East respiratory (MERS)-CoV infections. ${ }^{30-32}$ In order to design a new molecule for the treatment of Covid19, the remdesivir molecule used in the treatment was chosen as the lead compound. Remdesivir is metabolized into active nucleoside triphosphate (NTP) by the host; this metabolite competes with adenosine triphosphate (ATP) for incorporation into the nascent RNA strand. Therefore, molecular docking studies have been conducted based on NTP (the active form of remdesivir), and a target molecule that could be effective against Covid-19 was designed. The crystal structure of nsp12-nsp-7-nsp8 RNA-dependent RNA polymerase (RdRP) complex (PDB ID: 7BV2) was determined as the target protein. In recent studies with remdesivir, the protein (PDB ID: 7BV2) was preferred because these studies were carried out using this protein (Figure 1). ${ }^{18-20,34}$

One hundred thousand molecules were determined by filtering approximately two million compounds in the literature to create a virtual library. Docking studies were conducted using the compounds in the virtual library.

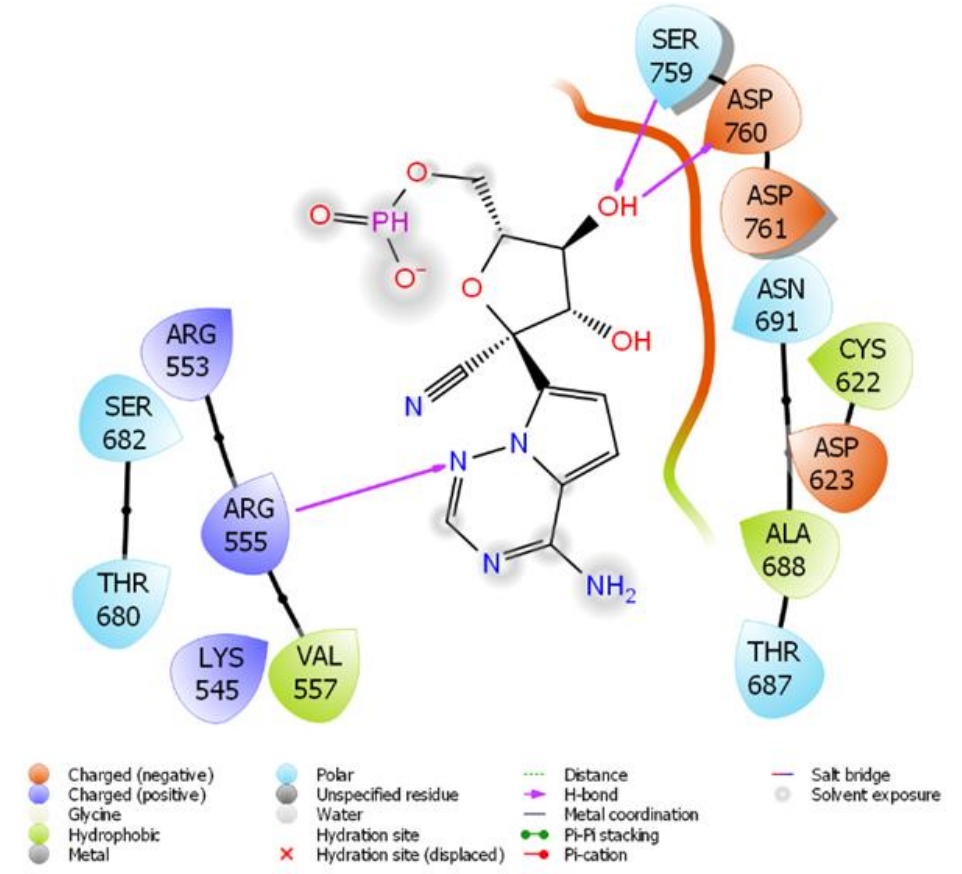

Figure 1. 2D interaction of NTP at the active site of the 7BV2 PDB-encoded protein 
While the docking score of NTP was found to be $-7,341 \mathrm{kcal} / \mathrm{mol}$, the docking scores of the five most active molecules were between $-7,554$ and $-8,695 \mathrm{kcal} / \mathrm{mol}$ (Table 1). It is noteworthy that the docking scores of compounds 1 and 2 (-8,695 and -8,046, respectively) are higher than the score of NTP.

Compound 1 has hydrogen bonding with ARG555 and ASP760; hydrophobic interaction with VAL557; charged (negative) interaction ASP623 and ASP761; charged (positive) interaction with LYS545; and polar interaction with SER682 and THR687 in the active zone of the receptor like NTP. Compound 1 also has hydrogen bonding with TYR619; hydrophobic interaction with ALA547, ILE548, PRO620, TRP617, and CYS813; polar interaction with SER549 and SER814; charged (negative) interaction with ASP618 and GLU811; and charged (positive) interaction with LYS621 and ARG836. Compound 2 has hydrogen bonding with ASP760; hydrophobic interaction with VAL557 and CYS622; charged (negative) interaction ASP623, ASP760, and ASP761; charged (positive) interaction with LYS545; and polar interaction with THR687 in the active zone of the receptor like NTP (Figure 2). Compound 2 also has hydrogen bonding with SER682 and cation-pi interaction with ARG555.

Table 1. The docking scores of the five most active compounds

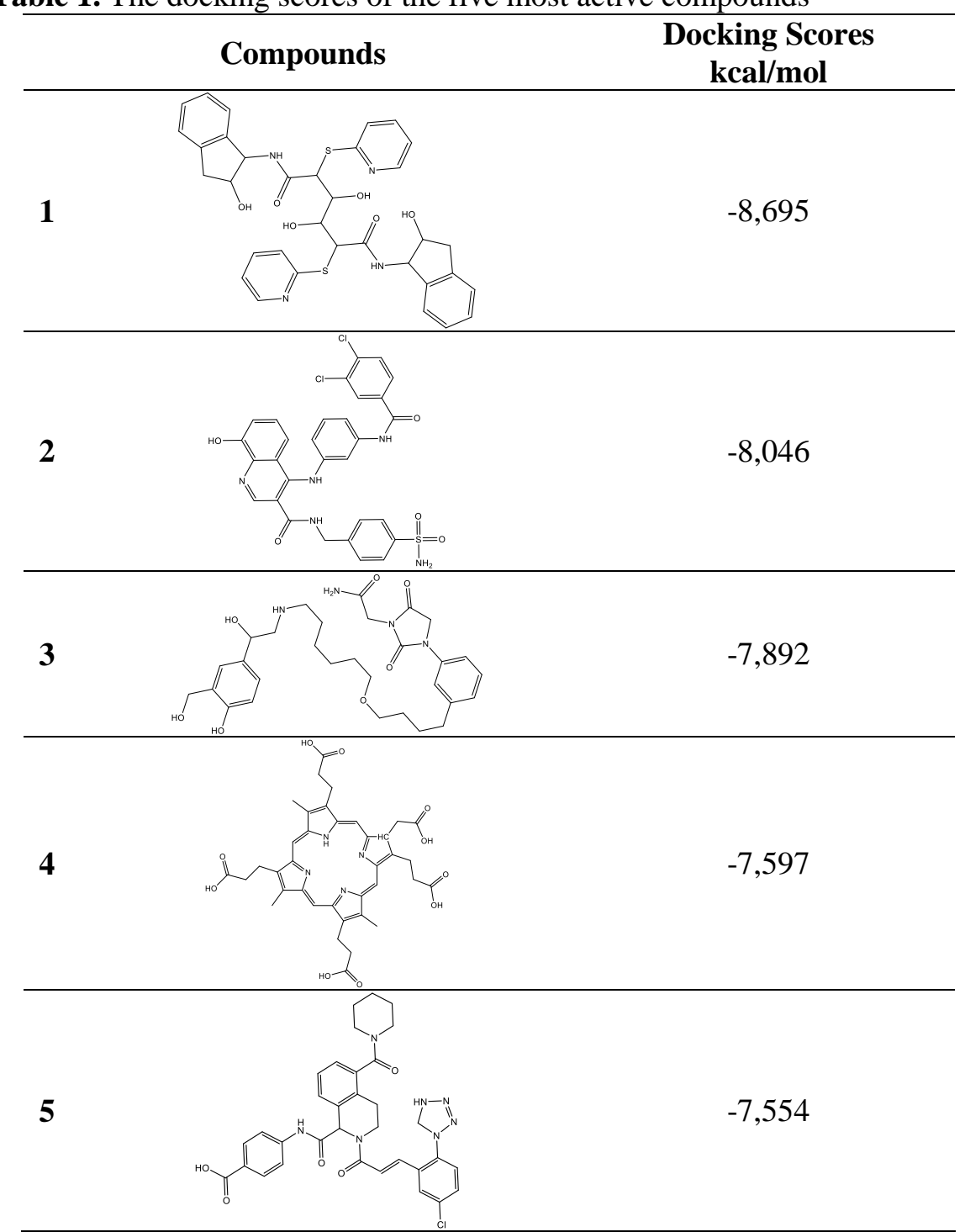




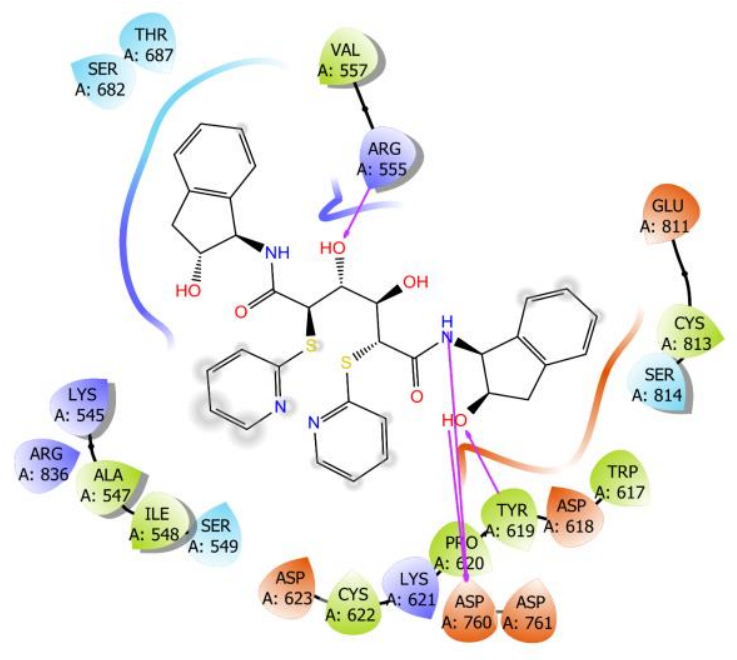

compound 1

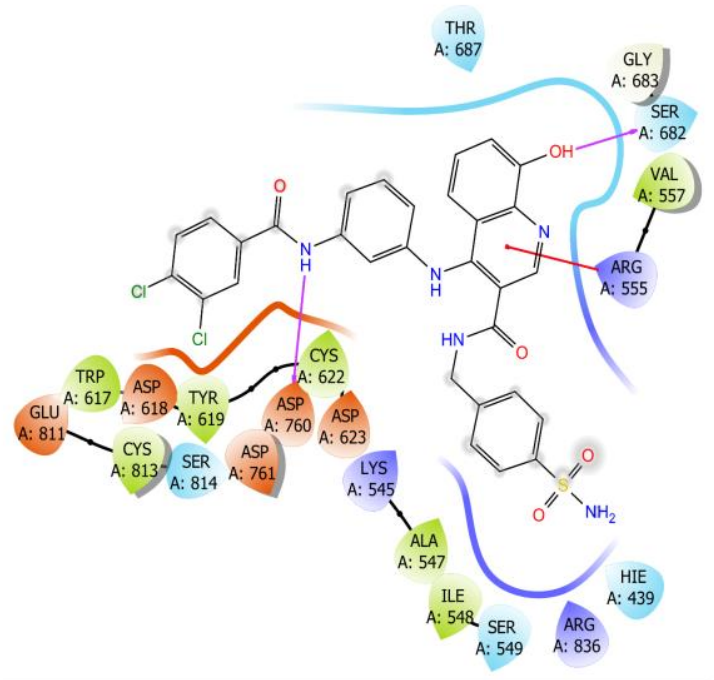

compound 2

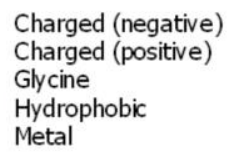

\begin{tabular}{|c|c|c|}
\hline Polar & $\cdots$. & Distance \\
\hline pecified residue & $\rightarrow$ & $\mathrm{H}$-bond \\
\hline & & Metal coordination \\
\hline $\begin{array}{l}\text { Hydration site } \\
\text { Hydration site (displaced) }\end{array}$ & $\bullet$ & $\begin{array}{l}\text { Pi-Pi stacking } \\
\text { Pi-cation }\end{array}$ \\
\hline
\end{tabular}

Polar Hydration site (displaced)

Pi-cation

Figure 2. 2D interaction of compound $\mathbf{1}$ and compound $\mathbf{2}$ at the active site of the 7BV2 PDB-encoded protein

When the interactions of the five compounds with the best docking scores with the receptor are examined, it is thought that their interactions with LYS545, VAL557, ARG555, ASP623, SER682, THR687, ASP760, and ASP761 may increase the activity due to their the docking scores. In order to develop more active compounds, various modifications have been made on the compound $\mathbf{1}$ to increase the interaction of the most active compound 1 with residues responsible for activity. It has been observed that the $-\mathrm{NH}$ and $-\mathrm{OH}$ groups in the compound $\mathbf{1}$ structure interact with residues by hydrogen bonding in the active site of the target protein. Therefore, eleven new compounds were designed by adding groups that can make hydrogen bonds such as $-\mathrm{NH}_{2},-\mathrm{OH}$, and $-\mathrm{F}$ to the structure of compound $\mathbf{1}$ (Figure 3 ).

\begin{tabular}{ccc}
\hline Comp. & $\mathbf{R}_{\mathbf{1}}$ & $\mathbf{R}_{\mathbf{2}}$ \\
\hline $\mathbf{6}$ & $-\mathrm{NH}_{2}$ & $=\mathrm{O}$ \\
$\mathbf{7}$ & $-\mathrm{F}$ & $=\mathrm{O}$ \\
$\mathbf{8}$ & $-\mathrm{OH}$ & $-\mathrm{OH}$ \\
$\mathbf{9}$ & $-\mathrm{OH}$ & $-\mathrm{NH}_{2}$ \\
$\mathbf{1 0}$ & $-\mathrm{OH}$ & $-\mathrm{F}$ \\
$\mathbf{1 1}$ & $-\mathrm{NH}_{2}$ & $-\mathrm{OH}$ \\
$\mathbf{1 2}$ & $-\mathrm{NH}_{2}$ & $-\mathrm{NH}_{2}$ \\
$\mathbf{1 3}$ & $-\mathrm{NH}_{2}$ & $-\mathrm{F}$ \\
$\mathbf{1 4}$ & $-\mathrm{F}$ & $-\mathrm{OH}$ \\
$\mathbf{1 5}$ & $-\mathrm{F}$ & $-\mathrm{NH}_{2}$ \\
$\mathbf{1 6}$ & $-\mathrm{F}$ & $-\mathrm{F}$ \\
\hline
\end{tabular}

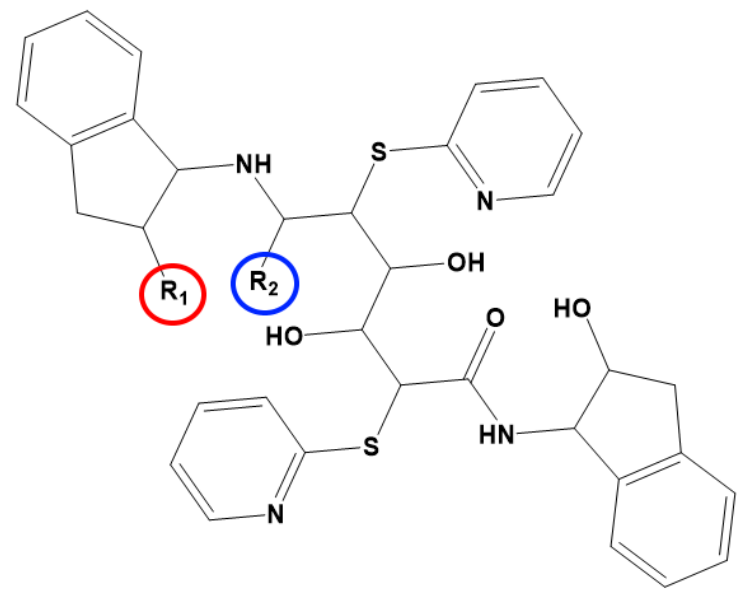

Figure 3. Newly designed derivatives of compound $\mathbf{1}$ 
Generally, there was no significant change in the docking scores of the other designed compounds compared to compound $\mathbf{1}$. However, the docking score of the compound obtained by adding the $-\mathrm{NH}_{2}$ and -OH groups (compound 11) was calculated as $-9.746 \mathrm{kcal} / \mathrm{mol}$. When the interaction of compound 11 with the receptor was examined, it was determined that the added $-\mathrm{NH}_{2}$ group had two new hydrogen bonds with ASP761and GLU811; had two salt bridges with ASP761 and GLU811; and significantly increased the docking score (Figure 4).

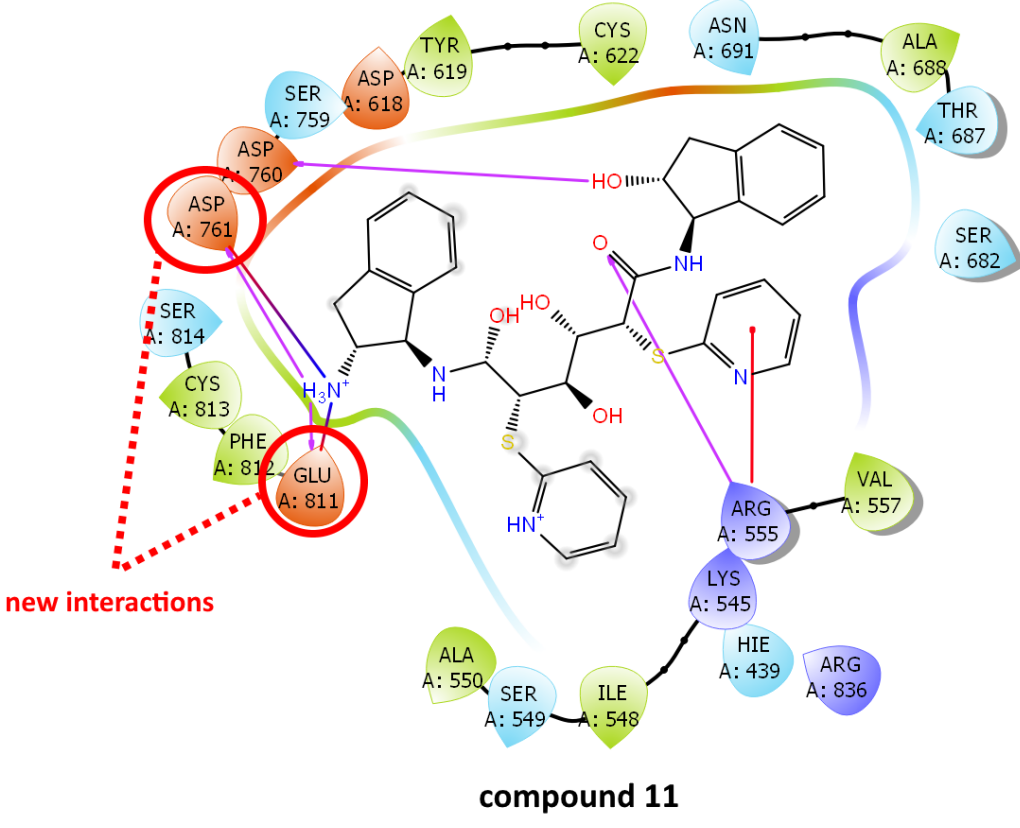

Figure 4. 2D interaction of compound $\mathbf{1 1}$ at the active site of the 7BV2 PDB-encoded protein

Table 2. Some predicted toxicological, ADME, and drug-like properties

\begin{tabular}{|c|c|c|c|}
\hline Parameters & Remdesivir & Compound 1 & Compound 11 \\
\hline \multicolumn{4}{|c|}{ Toxicological } \\
\hline Irritant $^{\mathrm{a}}$ & High & None & None \\
\hline Reproductive effects ${ }^{\mathrm{a}}$ & High & None & None \\
\hline Carcinogenic $^{\mathrm{a}}$ & High & None & None \\
\hline Mutagenic $^{\mathrm{a}}$ & None & None & None \\
\hline hERG inhibition ${ }^{\mathrm{b}}$ & Ambiguous & Ambiguous & Ambiguous \\
\hline \multicolumn{4}{|c|}{ ADME } \\
\hline $\begin{array}{l}\text { Human intestinal } \\
\text { absorption }^{\mathrm{b}}\end{array}$ & \multicolumn{2}{|c|}{ Moderately absorbedWell absorbed } & Well absorbed \\
\hline Plasma protein binding ${ }^{\mathrm{b}}$ & Weakly bound & Strog bound & Strog bound \\
\hline Caco2 permeability $^{\mathrm{b}}$ & Low & Low & Low \\
\hline \multicolumn{4}{|c|}{ Druglikeness } \\
\hline Drug-likeness score ${ }^{\mathrm{a}}$ & $-21,381$ & 3,711 & 3,864 \\
\hline MDDR-like rule ${ }^{b}$ & Nondrug like & Drug like & Drug like \\
\hline Lipinski's Rule of five ${ }^{b}$ & Non Suitable & Non Suitable & Non Suitable \\
\hline
\end{tabular}

${ }^{a}$ Determined by datawarrior v4.07.02.

${ }^{\mathrm{b}}$ Determined by pre-admet (https://preadmet.bmdrc.kr) 
Although the synthesized compounds have activity, they must have appropriate pharmacokinetic properties and have no toxic properties in order to be medicines for clinical use. Therefore, it is important to determine the properties of in-silico ADMET before synthesizing the compounds expected to have activity. The ADMET properties of the reference molecule remdesivir, compound $\mathbf{1}$ determined as a result of literature review, and compound $\mathbf{1 1}$ determined as a target molecule are given in Table 2.

Compound 11 is suitable for MDDR-like rules (No. Rings $\geq 3$, No. Rigid bonds $\geq 18$, and No. Rotatable bonds $\geq 6$ ), but it is not suitable for Lipinski's rule of five (hydrogen bond donors $\leq 5$, hydrogen bond acceptor $\leq 10$, molecular weight $\leq 500$, and $\mathrm{CLogP} \leq 5$ ) since its molecular mass is more than 500 daltons and it has more than five hydrogen bond donors. However, with respect to the toxicological parameters, compound $\mathbf{1 1}$ has no estimated mutagenic, carcinogenic, irritant, or reproductive effects. In the case of drug-like parameters, compound $\mathbf{1 1}$ can be considered as a potential oral drug, because it is wellabsorbed in the human intestine. The drug likeness value of compound $\mathbf{1 1}$ was calculated to be 3,864 . Since the drug similarity values of $80 \%$ of the drugs are positive, compound $\mathbf{1 1}$ can be considered a candidate drug.

When these properties were examined, it was seen that the toxic properties of compound $\mathbf{1 1}$ were more appropriate than remdesivir and compound 1. In addition, the ADME properties of compound $\mathbf{1 1}$ were determined to be suitable for drug likeness.

\section{Conclusion}

In this study, various in-silico studies such as developing molecular docking and the determination of ADMET properties were carried out in order to design an effective molecule against Covid-19. In this context, the compounds in the literature were scanned and the compounds expected to show the best activity against Covid-19 were determined (compounds $\mathbf{1}$ and 2). In order to design a newer, more active compound, various modifications were made on this compound $\mathbf{1}$ to reach the target molecule (compound 11). In insilico ADMET studies, it was determined that the target compound did not have predicted toxicity and its physicochemical properties were appropriate. Future studies will aim to synthesize the most active compound as $\mathbf{1 1}$ derivatives, examine their activities, and develop new compounds against Covid-19.

\section{ORCID}

Mehmet Abdullah Alagöz: 0000-0001-5190-7196

\section{References}

[1] Su, S.; Wong, G.; Shi, W.; Liu, J.; Lai, A.C.K.; Zhou, J.; Liu, W., Bi, Y.; Gao, G.F. Epidemiology, genetic recombination, and pathogenesis of coronaviruses. Trends Microbiol. 2016, 24, 490-502.

[2] Li, Q.; Guan, X., Wu, P.; Wang, X.; Zhou, L.; Tong, Y.; Ren, R.; Leung, K.S.M.; Lau, H.Y.; Wong, J.Y.; Xing, X.; Xiang, N. Early transmission dynamics in Wuhan, China, of novel coronavirus-infected pneumonia. New Engl. J. Med. 2020, 382, 1199-1207.

[3] https://www.who.int/emergencies/diseases/novel-coronavirus-2019?

[4] Velavan, T.P; Meyer, C.G. The COVID-19 epidemic. Trop. Med. Int. Health. 2020, 25(3),278-280.

[5] Yin, W.; Mao, C.; Luan, X.; Shen, D.; Shen, Q.; Su, H.; Wang, X.; Zhou,F.; Zhoa,W.; Gao, M.; Chang, S.; Xie, Y.; Tian, G.; Jiang, H.; Tao, S.; Shen, J.; Jiang, J.; Jiang, H.; Xu, Y.; Zang, S.; Zhang,Y. $\mathrm{Xu}, \mathrm{H}$.E. Structural basis for inhibition of the RNA-dependent RNA polymerase from SARS-CoV-2 by remdesivir. Science 2020, 368, 1499-1054.

[6] Carta, A.; Briguglio, I.; Piras, S.; Corona, P.; Boatto, G.; Nieddu, M.; Giunchedi, P.; Marongiu, M.E.; Giliberti, G.; Iuliano, F. Quinoline tricyclic derivatives. Design, synthesis and evaluation of the antiviral activity of three new classes of RNA-dependent RNA polymerase inhibitors. Bioorg. Med. Chem. 2011, 19(23), 7070-7084. 
[7] Goldman, J.D; , Lye, D.; Hui, D.S.; Marks, K.M.; Bruno, R.; Montejano, R.; Spinner, C.D.; Galli, M.; Ahn, M.Y.; Nahass, R.G.; Chen, Y.S.; SenGupta, D.S; Hyland, R.H.; Phil,D.; Osinusi, A.O.; Cao, H.; Blair, C.; Wei, X.; Gaggar, A.; Brainard, D.M.; Towner, W.J.; Munoz, J.; Mullane, K.M.; Marty, F.M.; Tashima, K.T.; Diaz, G.; Subramanian, A. Remdesivir for 5 or 10 days in patients with severe covid-19. New Engl. J. Med. 2020, 383(19), 1827-1837.

[8] https://www.bmj.com/content/369/bmj.m2610.full

[9] Booth, C.M.; Matukas, L.M.; Tomlinson, D.A. Rachlis, A.R.; Rose, D.B.; Dwosh,H.A.; Walmsley, S.L.; Mazzulli, T.; Avendano, M.; Derkach, P.; Ephtimios, I.E.; Kitai, I.; Mederski, B.D.; Shadowitz, S.B.; Gold, W.L.; Hawryluck, L.A.; Rea, E.; Chenkin, J.S.; Cescon, D.W.; Poutanen, S.M.; Detsky, A.S. PhDClinical features and short-term outcomes of 144 patients with SARS in the greater Toronto area. JAMA. 2003, 289 (21), 2801-2809.

[10] Stockman, L.J.; Bellamy, R.; Garner, P. SARS: systematic review of treatment effects. PLoS Med. 2006, 3(9), 1525-1531.

[11] Wang, M., Cao, R.; Zhang, L.; Yang, X.; Liu, J.; Xu, M. Shi, Z.; Hu, Z.; Zhong, W.; Xiao, G. Remdesivir and chloroquine effectively inhibit the recently emerged novel coronavirus (2019-nCoV) in vitro. Cell Res. 2020, 30, 269-271.

[12] Weiss, S.R.; Navas-Martin, S. Coronavirus pathogenesis and the emerging pathogen severe acute respiratory syndrome coronavirus. Microbiol. Mol. Biol. Rev. 2005, 69(4), 635-664.

[13] Fehr, A.R.; Perlman, S. Coronaviruses: an overview of their replication and pathogenesis. Methods Mol. Biol. 2015, 1282, 1- 23.

[14] Azizeh, A.; Jahan, B.G.; Fatemeh, G. Computer aided drug design for multi-target drug design: sar /qsar, molecular docking and pharmacophore methods. Curr.Drug Targets. 2017, 18(5), 556-575.

[15] Brogi, S.; Ramalho, T.C.; Kuca, K.;Medina-Franco, J.L.; Valko, M. Editorial: In silico methods for drug design and discovery frontiers in chmistry. Front. Chem. 2020, 8, Article 612, 8 pages.

[16] Algul, O.; Ersan R.H.; Alagoz, M.A.; Duran, N.; Burmaoglu, S. An efficient synthesis of novel diheterocyclic benzazole derivatives and evaluation of their antiproliferative activities. J. Biomol. Struct. Dyn. 2020.13 pages. https://doi.org/10.1080/07391102.2020.1803966

[17] Jin, Z.; Du, X.; Xu, Y.; Deng, Y.; Liu, M.; Zhao, Y.; Zhang, B.; Li, X. Zhang, L.; Peng, C.; Duan, Y.; Yu, J.; Wang, L.; Yang, K.; Liu, F.; Jiang, R.; Yang, X.; You, T.; Liu, X.; Yang, X.; Bai, F.; Liu, H. Liu, H.; Guddat, L.W.; Xu, W.; Xiao, G.; Qin, G.; Shi, Z.; Jiang, H.; Rao, Z.; Yang, H. Structure of M Mro $^{\text {pro }}$ from SARS-CoV-2 and discovery of its inhibitors. Nature 2020, 582, 289-293.

[18] Gervasoni, S.; Vistoli, G.; Talarico, C.; Manelfi, C.; Beccari, A.R.; Studer, G.; Tauriello, G.; Waterhouse, A.M.; Schwede, T.; Pedretti, A. A Comprehensive mapping of the druggable cavities within the SARS-CoV2 therapeutically relevant proteins by combining pocket and docking searches as implemented in pockets 2.0. Int. J. Mol. Sci. 2020, 21, Article 5152, 17 pages.

[19] Amiriana, E.S.; Levyb, J.K. Current knowledge about the antivirals remdesivir (GS-5734) and GS441524 as therapeutic options for coronaviruses. One Health. 2020, 9, Article 100128, 7 pages.

[20] Al-Masoudi, N.A.; Elias, R.S.; Saeed, R. Molecular docking studies of some antiviral and antimalarial drugs via bindings to $3 \mathrm{cl}$-protease and polymerase enzymes of the novel coronavirus (SARSCoV-2). Biointerface Res. Appl. Chem. 2020, 10(5), 6444 - 6459.

[21] Banks, J. L.; Beard, H. S.; Cao, Y. X.; Cho, A. E.; Damm, W.; Farid, R.; Felts, A.K.; Halgren, T.A.; Mainz, D. T.; Maple, J.R.; Murphy, R.; Philipp, D.M.; Repasky, M.P.; Zhang, L.Y.; Berne, B.J.; Richard A.F.; Gallicchio, E.; Levy, R.M. Integrated modeling program, applied chemical theory. J. Comput. Chem. 2005, 26, 1752-1780.

[22] Friesner, R.A.; Murphy, R.B.; Repasky, M.P.; Frye, L.L.; Greenwood, J.R.; Halgren, T.A.; Sanschagrin, P.C.; Mainz, D.T. Extra precision glide: docking and scoring incorporating a model of hydrophobic enclosure for proteinligand complexes. J. Med. Chem. 2006, 49, 6177-6196.

[23] Ersan, R.H.; Alagoz, M.A.; Ertan-Bolelli, T.; Duran, N.; Burmaoglu, S.; Algul, O. Head-to-head bisbenzazole derivatives as antiproliferative agents: design, synthesis, in vitro activity, and SAR analysis. Mol. Divers. 2020, 13 pages. https://doi.org/10.1007/s11030-020-10115-0

[24] Enríquez-Mendiola, D.; Téllez-Valencia, A.; Sierra-Campos, E.; Campos-Almazán, M.; Valdez-Solana,M.; Palacio-Gastélum, M.G.; Avitia-Domínguez, C. Kinetic and molecular dynamic studies of inhibitors of 
shikimate dehydrogenase from methicillin-resistant Staphylococcus aureus. Chem. Biol. Drug Des. 2019, 94, 1504-1517.

[25] Lipinski, C.A.; Lombardo, L.; Dominy, B.W.; Feeney, P.J. Experimental and computational approaches to estimate solubility and permeability in drug discovery and development settings, Adv. Drug Deliv. Rev. 2001, 46, 3- 25.

[26] El Kerdawy, A.M.; Osman, A.A.; Zaater, M.A. Receptor-based pharmacophore modeling, virtual screening, and molecular docking studies for the discovery of novel GSK-3 $\beta$ inhibitors. J. Mol. Model. 2019, 25, Article 171, 21 pages.

[27] Bhole, R. P.; Bonde, C. G.; Bonde, S. C.; Chikhale, R. V.; Wavhale, R. D. Pharmacophore model and atombased 3D quantitative structure activity relationship (QSAR) of human immunodeficiency virus-1 (HIV-1) capsid assembly inhibitors. J. Biomol. Struct. Dyn. 2020. 11 pages. DOI:10.1080/07391102.2020.1715258

[28] Koulgi, S.; Jani, V.; Uppuladinne, M.V.N.; Sonavane, U.; Joshi, R. Remdesivir-bound and ligand-free simulations reveal the probable mechanism of inhibiting the RNA dependent RNA polymerase of severe acute respiratory syndrome coronavirus. RSC $A d v . \mathbf{2 0 2 0}, 10,26792$.

[29] Lo, M.K.; Jordan, R.; Arvey, A. GS-5734 and its parent nucleoside analog inhibit filo-, pneumo-, and paramyxoviruses. Sci Rep. 2017, 7, 1-7.

[30] Sheahan, T.P.; Sims, A.C.; Graham, R.L. Menachery, V.D.; Gralinski,L.E.; Case, J.B.; Leist, S.R.; Pyrc, K.; Feng, J.Y.; Trantcheva, I.; Bannister, R.; Park, Y.; Babusis, D.; Clarke, M.O.; Mackman, R.L.; Spahn, J.E.; Palmiotti, C.A.; Siegel, D.; Ray, A.S.; Cihlar, T.; Jordan, R.; Denison, M.R.; Baric, R.S.Broad-spectrum antiviral GS-5734 inhibits both epidemic and zoonotic coronaviruses. Sci. Transl. Med. 2017, 9, Article 3653, 10 pages.

[31] Warren, T.K.; Jordan, R.; Lo, M.K.; Ray, A.S.; Mackman, R.L.; Soloveva, V.; Siegel, D.; Perron, M. Bannister, R.; Hui, H.C.; Larson, N.; Strickley, R.; Wells, J.; Stuthman, K.S.; Tongeren, S.A.V.; Garza, N.L.; Donnelly, G.; Shurtleff, A.C.; Retterer, C.J.; Gharaibeh, D.; Zamani, R.; Kenny, T.; Eaton, B.P.; Grimes, E.; Welch, L.S.; Gomba, L.; Wilhelmsen, C.L.; Nichols, D.K.; Nuss, J.E.; Nagle, E.R.; Kugelman, J.R.; Palacios, G.; Doerffler, E.; Neville, S.; Carra, E.; Clarke, M.O.; Zhang, L.; Lew, W.; Ross, B.; Wang, Q.; Chun, W.; Wolfe, L.; Babusis, D.; Park, Y.; . Stray, K.M.; Trancheva, I.; Feng, J.Y.; Barauskas, O.; Xu, Y.; Wong, P.; Braun, M.R.; Flint, M.F.; McMullan, L.K.; Chen, S.S.; Fearns, R.; Swaminathan, S.; Mayers, D.L.; Spiropoulou, C.F.; Lee,W.A.; Nichol, S.T.; Cihlar, T.; Bavari, S.Therapeutic efficacy of the small molecule GS-5734 against Ebola virus in rhesus monkeys. Nature 2016, 531, 381-385.

[32] Brown, A.J.; Won, J.J.; Graham, R.L.; Dinnon, K.H.; Sims, C.A.; Feng, J.Y.; Cihlar, T.; Denisson, M.R.; Baric, R.S.; Sheahan, T.P. Broad spectrum antiviral remdesivir inhibits human endemic and zoonotic deltacoronaviruses with a highly divergent RNA dependent RNA polymerase. Antiviral Res. 2019, 169, Article 104541, 10 pages.

[33] Sheahan, T.P.; Sims, A.C.; Leist, S.R.; Schäfer, A.; Won, J.; Brown, A.J. Montgomery, S.A.; Hogg, A.; Babusis, A.; Clarke, M.O.; Spahn, J.E.; Bauer, B.; Sellers, S.; Porter, D.; Feng, J.Y.; Cihlar, T.; Jordan, R.; Denison M.R.; Baric, R.S. Comparative therapeutic efficacy of remdesivir and combination lopinavir, ritonavir, and interferon beta against MERS-CoV. Nature Commun. 2020, 11, Article 222, 14 pages.

[34] Wit,E.; Feldmann, F.; Cronin, J. Jordan, R.; Okumura, A.; Thomas, T.; Scott, D.; Cihlar, T.; Feldmann, H. Prophylactic and therapeutic remdesivir (GS-5734) treatment in the rhesus macaque model of MERS-CoV infection. Proc. Natl. Acad. Sci. 2020, 117, 6771-6776

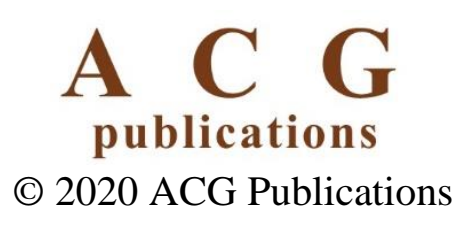

